\title{
Axonal Conduction Block as a Novel Mechanism of Prepulse Inhibition
}

\author{
Anne H. Lee, Evgenia V. Megalou, Jean Wang, and William N. Frost \\ Department of Cell Biology and Anatomy, The Chicago Medical School, Rosalind Franklin University of Medicine and Science, North Chicago, Illinois 60064
}

In prepulse inhibition (PPI), the startle response to a strong, unexpected stimulus is diminished if shortly preceded by the onset of a different stimulus. Because deficits in this inhibitory gating process are a hallmark feature of schizophrenia and certain other psychiatric disorders, the mechanisms underlying PPI are of significant interest. We previously used the invertebrate model system Tritonia diomedea to identify the first cellular mechanism for PPI-presynaptic inhibition of transmitter release from the afferent neurons (S-cells) mediating the startle response. Here, we report the involvement of a second, more powerful PPI mechanism in Tritonia: prepulse-elicited conduction block of action potentials traveling in the startle pathway caused by identified inhibitory interneurons activated by the prepulse. This example of axo-axonic conduction block-neurons in one pathway inhibiting the propagation of action potentials in another-represents a novel and potent mechanism of sensory gating in prepulse inhibition.

\section{Introduction}

When a startle stimulus is closely preceded by the onset of a weaker stimulus of almost any sensory modality, the normally robust startle response is diminished. This innate inhibitory phenomenon is known as prepulse inhibition (PPI). The universality of PPI across animal species, from humans and other vertebrates (Johansson et al., 1995; Braff et al., 2001; Geyer et al., 2001; Winslow et al., 2002) to invertebrates (Mongeluzi et al., 1998), suggests that the inhibitory sensory gating circuitry exposed by the PPI paradigm plays a fundamental role in sensory processing.

Many have speculated that an important function of PPI is to reduce distractibility, by preventing closely following stimuli from interfering with the processing of an initial input (Graham, 1992; Hoffman and Ison, 1992; Braff et al., 2001; Hamm et al., 2001). Interest in PPI has increased markedly since it was found to be deficient in schizophrenia and certain other neurological and psychiatric disorders (Braff et al., 1992; Braff et al., 2001; Geyer et al., 2001; Hamm et al., 2001). The PPI deficit of schizophrenia has been linked to the distractibility, thought disorder, and psychosis associated with this disease (Bakshi et al., 1994; Perry and Braff, 1994; Johansson et al., 1995; Karper et al., 1996;

Received Jan. 12, 2012; revised Aug. 20, 2012; accepted Aug. 27, 2012.

Author contributions: A.H.L., E.V.M., and W.N.F. designed research; A.H.L., E.V.M., and J.W. performed research;

A.H.L., E.V.M., and W.N.F. analyzed data; A.H.L. and W.N.F. wrote the paper.

This work was supported by NIH Grants DA16320, NS36500, and NS060921, and by the Fred B. Snite Foundation.

We thank Lise Eliot for comments on this manuscript.

The authors declare no competing financial interests.

Correspondence should be addressed to William N. Frost, Department of Cell Biology and Anatomy, The Chicago

Medical School, Rosalind Franklin University of Medicine and Science, 3333 Green Bay Road, North Chicago, Illinois 60064. E-mail:William.frost@rosalindfranklin.edu.

A. H. Lee's present address: Brown University-Rhode Island Hospital, Department of Pathology, Division of Neuropathology, 593 Eddy Street, Providence, RI 02903.

E. V. Megalou's present address: Institute of Molecular Biology and Biotechnology, Foundation for Research and Technology, Heraklion 71110, Crete, Greece.

DOI:10.1523/JNEUROSCI.0160-12.2012

Copyright $\odot 2012$ the authors $\quad 0270-6474 / 12 / 3215262-09 \$ 15.00 / 0$
Kumari et al., 1999; Weike et al., 2000; Braff et al., 2001; Friedman, 2004; Barak, 2009). Recent findings that the PPI deficit precedes the overt symptoms of schizophrenia are consistent with a possible role in their development (Quednow et al., 2008; Ziermans et al., 2011, 2012). Motivated by its clinical relevance, efforts are underway to identify the neuronal mechanisms mediating PPI (Koch et al., 1993; Swerdlow and Geyer, 1993; Fendt and Koch, 1999; Braff et al., 2001; Fendt et al., 2001; Geyer et al., 2001; Homma et al., 2002; Yeomans et al., 2006; Bosch and Schmid, 2008; Schofield and Motts, 2009). While these studies have identified relevant brain areas and transmitter systems, specific cellular mechanisms for vertebrate PPI are yet to be elucidated.

Invertebrates, with their simpler nervous systems comprised of small numbers of large, individually identifiable neurons, provide a powerful tool for working out basic CNS mechanisms relevant across the animal kingdom (Sandeman, 1999; Selverston, 1999; Pittenger and Kandel, 2003; Bouret and Sara, 2005; Sattelle and Buckingham, 2006; Clarac and Pearlstein, 2007). We previously demonstrated that PPI occurs in the marine mollusk Tritonia diomedea, using a tactile prepulse to inhibit the animal's escape startle response to an aversive skin shock stimulus (Mongeluzi et al., 1998). A prepulse-activated interneuron, Pleural-9 (Pl-9), was found to be necessary and sufficient for prepulse skin stimuli to produce PPI of the swim motor program (SMP) underlying this behavioral response. Pl-9 accomplishes this, in part, by producing presynaptic inhibition of the synapses made by the startle pathway afferent neurons (S-cells) onto their target interneurons, reducing their ability to evoke the swim (Frost et al., 2003). Here we describe a novel, and even more potent mechanism contributing to PPI-prepulse-elicited conduction block by $\mathrm{Pl}-9$ of action potentials propagating in the startle pathway. Such axo-axonic conduction block, the inhibition of actively propagating action potentials in the axons of one pathway by axons of another pathway, is well suited to play a role in a variety of network gating functions. 


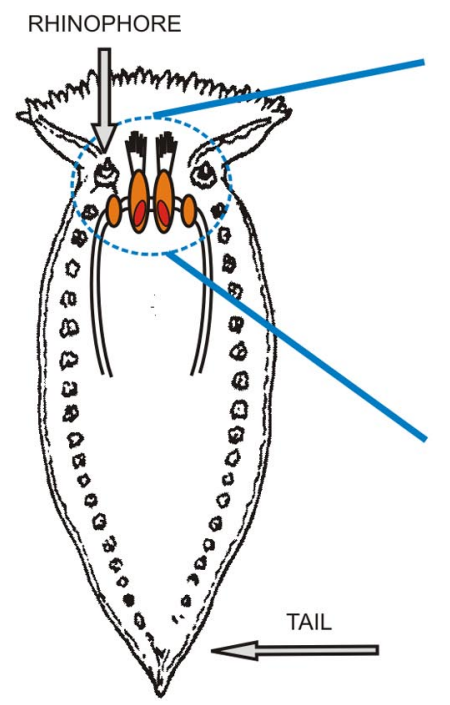

\section{Isolated brain preparation}

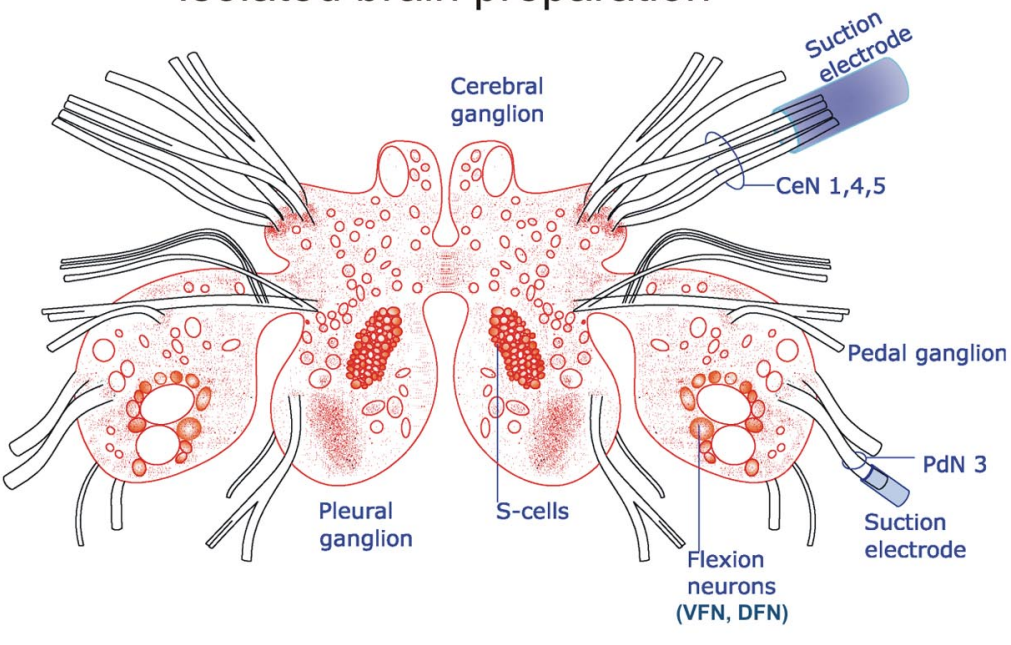

Figure 1. Tritonia and the isolated brain preparation. Dorsal view, showing cerebral, pleural, and pedal ganglia. Suction electrodes are shown attached to nerves used to deliver the prepulse inhibitory stimulus (CeN 1,4,5) and the startle stimulus (PdN 3). Also shown are the locations of the S-cell afferent neurons as well as several of the VFN and DFN flexion neurons.

\section{Materials and Methods}

Animals

Tritonia diomedea were obtained from Living Elements and maintained at $11^{\circ} \mathrm{C}$ in recirculating artificial seawater systems (Instant Ocean, Aquarium Systems). Animals were fed live sea pens (Ptilosarcus gurneyi), one of their natural prey.

\section{Isolated brain preparation}

The brain (fused cerebral-pleural ganglia and pedal ganglia, Fig. 1) was excised from the animal and pinned dorsal side up onto the Sylgard (Dow Corning) covered surface of a recording chamber perfused at $4^{\circ} \mathrm{C}$ with artificial seawater. The connective tissue sheath enclosing the fused left or right cerebral-pleural ganglia was surgically removed, and for certain experiments, the sheath enclosing the pedal ganglion was also removed, exposing the neurons for intracellular recording. Pedal Nerve 3 [PdN3; for nomenclature, see the study by Willows et al. (1973)] ipsilateral to the desheathed half of the brain was drawn into a polyethylene suction electrode connected to a stimulator. Selected groups of cerebral ganglion nerves were drawn into another suction electrode connected to a second stimulator. The perfusion temperature was then raised to $11^{\circ} \mathrm{C}$ for the duration of each experiment.

\section{Semi-intact preparation}

Individual Tritonia were anesthetized with an injection of $45 \mathrm{ml}$ of 350 $\mathrm{mm} \mathrm{MgCl}_{2}$ into the body cavity. Subsequently, a longitudinal incision was made along the ventral and dorsal body walls and all internal organs were removed, sparing the nervous system. This semi-intact preparation was then positioned dorsal side up in a chamber with the brain exposed and secured with minuten pins to the Sylgard surface of a $1 \mathrm{~cm}$ diameter post rising from the chamber floor. A thin cylindrical sleeve containing slits to allow passage of the nerves was then raised around the brain. Initially, the brain chamber was perfused at $4^{\circ} \mathrm{C}$ with artificial sea water. During this period the connective tissue sheath enclosing the pedal ganglia, or the fused cerebral-pleural ganglia, was surgically removed, exposing the neurons for intracellular recording. In experiments using skin shock prepulses, the ends of Teflon-coated silver wires were stripped of insulation, bent into a simple hook, and pushed with a hypodermic needle into the skin in the area that included the rhinophore, part of the oral veil, and the nearby lateral body wall. PdN3 was cut on the side ipsilateral to the desheathed half of the brain, and its proximal stump was drawn into a polyethylene suction electrode connected to a stimulator used to elicit startle pathway orthodromic S-cell action potentials. The brain and body chambers were then perfused at $11^{\circ} \mathrm{C}$ for the duration of each experiment.
Identification and selection of neurons

The Tritonia swim network has been described in previous studies, and consists of afferent neurons (S-cells), trigger- and gating-type command neurons, central pattern generator (CPG) neurons, and flexion neurons (Fig. 2A) (Getting, 1983; Frost et al., 2001, 2003). Neurons were recorded intracellularly using 15-40 $\mathrm{M} \Omega$ electrodes filled with $3 \mathrm{~m} \mathrm{KAc} \mathrm{or} 3 \mathrm{~m} \mathrm{KCl}$.

S-cells. These CNS afferent neurons for the animal's escape swim startle response were identified based on their location, size, color, lack of activity at rest, and response to electrical stimulation (Getting, 1976; Megalou et al., 2009). The S-cells form a bilateral cluster of $\sim 100$ orangepigmented $\sim 50 \mu \mathrm{m}$ diameter neurons per cluster (Fig. 1). Each cluster extends diagonally on the dorsal side of the pleural ganglion, from the margin of the central commissure to the boundary near the entrance of pleural nerve 1 (PIN1). The majority of the S-cell cluster is located just beneath the TGN neurons (Getting, 1983), which lie on the surface of the dorsal pleural ganglia. The S-cells are silent at rest, and display an occasional IPSP.

$\mathrm{Pl}$-9. Inhibitory interneuron Pl-9 was identified as in our prior study (Frost et al., 2003). Each of the estimated 1-2 Pl-9 neurons in each pleural ganglion receives direct monosynaptic EPSPs from the ipsilateral S-cells, and in turn produces monosynaptic IPSPs bilaterally onto all S-cells. To locate Pl-9, an intracellular electrode was first used to penetrate an S-cell. A second electrode was then used to blindly penetrate neurons one cell layer below the surface at the known location of Pl-9 until it was encountered, as indicated by the penetrated neuron's production of 1-for-1, short and constant latency IPSPs onto the S-cell with each action potential, and its receipt of 1-for-1 short and constant latency EPSPs from ipsilateral S-cells.

Other neurons. In many experiments, the cerebral cell 2 (C2) or dorsal swim interneuron (DSI) CPG interneurons or their target dorsal flexion neurons (DFNs) and ventral flexion neurons (VFNs) were penetrated with intracellular electrodes to provide a monitor of the occurrence of the SMP. These well described neurons (Hume et al., 1982; Getting, 1983) are located on the dorsal surface of the cerebral (C2, DSI) and pedal (DFN, VFN) ganglia.

\section{Data analysis}

For experiments testing for the effect of the prepulse stimulus on mean data measures, such as the number of cycles of the swim motor program or the number of action potentials in a train that propagated successfully to the S-cell soma, a one-way repeated-measures ANOVA was used to test for overall effect of treatment, followed by Bonferroni post hoc tests for individual pairwise comparisons (SigmaPlot, Systat Software). For 

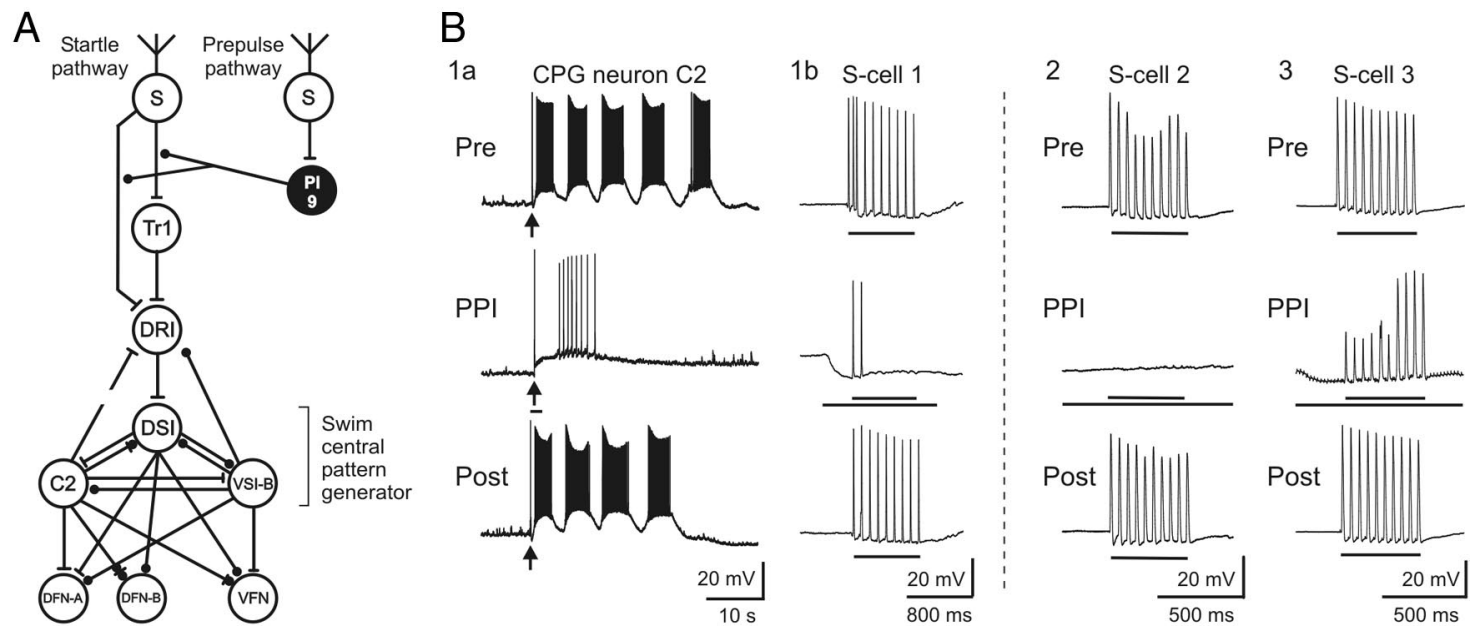

Figure 2. Prepulse stimuli block the swim motor program and the propagating S-cell action potentials that elicit it. $A$, Swim circuit, showing PI-9 connections to $S$-cell axons, which produce conduction block of orthodromic action potentials in the startle pathway. Synapses with bars are excitatory, those with black circles are inhibitory. Synapses with combinations of bars and circles produce multiple component PSPs. B, PPI block of the SMP and simultaneously recorded S-cell action potential propagation. B1, A PdN3 stimulus $(9$ pulses, $10 \mathrm{~Hz}$, arrow) elicited a 5 cycle SMP, monitored in CPG neuron C2 ( $\boldsymbol{a}$, Pre), and a train of S-cell action potentials that propagated successfully from their axons in PdN3 to the soma recording site in the pleural ganglion ( $\boldsymbol{b}$, Pre). Horizontal bars in all S-cell panels indicate periods of nerve stimulation. Two minutes later, a CN 1,4,5 stimulus ( $1.45 \mathrm{~s}, 50 \mathrm{~Hz}$ ) beginning $0.34 \mathrm{~s}$ before the PdN3 stimulus blocked the SMP (a, PPI) and also prevented the arrival of all but two of the S-cell action potentials elicited by the PdN3 stimulus (b, PPI; longer line indicates period of CN stim, shorter line the period of PdN3 stim). Two minutes later, a PdN3-alone stimulus elicited a 4 cycle SMP ( $\boldsymbol{a}$, Post) and a train of orthodromic S-cell action potentials that all propagated successfully to the soma $(\boldsymbol{b}$, Post). $\boldsymbol{B 2}$, In a second preparation, the SMP block (data not shown) was accompanied by total block of propagating S-cell action potentials. B3, In a third preparation, the SMP block (data not shown) was accompanied by failed active propagation (short spikes) of six of the 10 orthodromic S-cell action potentials elicited by the PdN3 stimulus train. Due to the pseudo-unipolar structure of Tritonia neurons, peripherally initiated S-cell action potentials do not pass through the soma on their way to the terminals. The soma recordings are thus indicative of propagation in the central processes.

experiments testing for the effect of different prepulse-startle intervals on whether or not a single startle-elicited action potential reached the soma, a Cochran Q test was used to test for overall effect of treatment, followed by Marascuilo and McSweeney post hoc tests to identify the intervals that produced significant conduction block (Statistica, StatSoft). For experiments testing for the ability of interneuron Pl-9 to produce conduction block of a single peripherally initiated action potential, a McNemar test for dichotomous nominal scale variables was used (SigmaPlot).

\section{Results}

The aim of the present study was to evaluate the possibility that prepulse stimuli may inhibit startle responses in part by blocking the propagation of startle pathway action potentials, specifically in the axons of the S-cell afferent neurons of Tritonia's startle pathway. The standard paradigm used throughout the study was to bracket PPI tests between startle-alone tests, to control for the possibility that any loss of responsiveness might be due to progressively accumulating habituation or accommodation, rather than PPI.

\section{Prepulse nerve stimuli produce PPI of the swim motor program, and conduction block of S-cell action potential trains}

The study began with the development of an isolated brain preparation for studying PPI, where well controlled nerve stimuli could be used for both the prepulse and startle stimuli (Fig. 1). Each experiment consisted of three stimulus trials, delivered $\sim 2$ min apart. On the first and third trials, a stimulus was delivered to PdN3 alone, a peripheral nerve that innervates the animal's tail. In every case this stimulus elicited an SMP, monitored via sharp electrodes inserted into identified swim network neurons (PdN3 stimuli consisted of $9-10$ pulses, $10-30 \mathrm{~Hz}$ trains of 3-50 V, 2-5 ms pulses). On the second trial, the PdN3 stimulus began $250-$ $1000 \mathrm{~ms}$ after the onset of a prepulse stimulus train to cerebral ganglion nerves 1,4 , and 5 , which innervate the animal's head (the prepulse stimulus consisted of a $0.5-2.5 \mathrm{~s}$ train of $20-50 \mathrm{~Hz}$, $7-20 \mathrm{~V}, 2-5 \mathrm{~ms}$ pulses). We found that in all nine preparations using this stimulus procedure, the prepulse stimulus completely blocked the SMP response to the startle stimulus (Fig. 2 B1a; first trial $=3.2 \pm 0.3$ cycles, PPI trial $=0.0 \pm 0.0$ cycles, third trial $=$ $3.0 \pm 0.2$ cycles $)$. A one-way between-subjects ANOVA indicated a significant overall effect of the presence of the prepulse for the three trials $\left(F_{(2,8)}=60.54, p<0.001\right)$. Post hoc Bonferroni comparisons indicated that the mean number of SMP cycles elicited by the first PdN3-alone trial versus the PPI trial were significantly different from one another $(t=9.85, p<0.001)$, as they were for the PPI trial versus the second PdN3-alone trial $(t=9.17, p<$ 0.001). The numbers of SMP cycles elicited on the two PdN3alone stimulus trials were not significantly different from one another. The reliable occurrence of an SMP on the second PdN3alone trial indicates that the SMP failure on the PPI trial can be attributed to the presence of the prepulse, rather than to any developing habituation of the SMP to the repeated $\mathrm{PdN} 3$ stimulus.

In four of the above experiments, S-cells were impaled with intracellular electrodes, to monitor spike propagation during PPI of the motor program. Each S-cell innervates the skin via axons in one or more peripheral nerves (Getting, 1976; Slawsky, 1979). In all cases we chose $\mathrm{S}$-cells that had axons in PdN3 but not cerebral neurons (CNs) 1,4 , or 5 , as determined by the arrival of action potentials in the $\mathrm{S}$-cell soma recording site in response to peripheral nerve stimulation. Once initiated, S-cell action potentials propagate orthodromically along their axons in PdN3 into the pedal ganglion, and then continue via a commissure into the pleural ganglion, where the S-cell somata and postsynaptic target neurons are located. The stimulus voltage was adjusted at the start of each experiment to be just strong enough to reliably elicit an orthodromic action potential that propagated successfully to the S-cell soma recording site. On PPI trials, a stimulus was applied to the cerebral nerves beginning at various intervals before 
the PdN3 stimulus, and its ability to block successful propagation of the PdN3-elicited S-cell action potential to the soma was evaluated. In all cases, PPI trials were bracketed by PdN3-alone trials to ensure that propagation failures were related to the presence of the prepulse stimulus and not to an inability of the PdN3 stimulus to trigger an action potential in the S-cell axon. In the four experiments with co-impaled S-cells, PdN3 stimulus-elicited action potentials propagated normally to the soma on all PdN3alone trials. In contrast, when the SMP was blocked on the PPI trial, the S-cell action potentials elicited by the PdN3 stimulus either failed to arrive at the $S$-cell soma $(N=2$ preparations; Fig. $2 B 1 \mathrm{~b}, B 2)$ or arrived $50 \%$ or more reduced in amplitude $(N=2$ preparations; Fig. 2B3). The amplitude reduction is consistent with the inbound action potential having been blocked close enough to the soma recording site that a remnant reached it via electrotonic conduction.

Conduction block of action potentials in the startle pathway would represent a novel and potent cellular mechanism for PPI. To investigate this further, we conducted a more extensive isolated brain experiment focused on this phenomenon, with no accompanying monitor of the SMP. As before, S-cells were selected that were specific to the startle pathway: they fired 1-for-1, constant latency action potentials on each pulse of the 10 pulse PdN3 stimulus train, and were also not activated by the prepulse stimulus. In this experiment, three identical 10-pulse PdN3 stimulus trains $(20 \mathrm{~Hz}, 0.5 \mathrm{~s}, 3-7 \mathrm{~V}, 2 \mathrm{~ms})$ were administered $\sim 1 \mathrm{~min}$ apart. On the middle trial, the PdN3 stimulus train began $1 \mathrm{~s}$ after the onset of a prepulse stimulus train to cerebral nerves 1,4 , and $5(20 \mathrm{~Hz}, 2.5 \mathrm{~s}, 15-22.5 \mathrm{~V})$. Of $19 \mathrm{~S}$-cells examined in 9 preparations, 13 underwent virtually complete conduction block, with only 1 of the 130 action potentials initiated in $\mathrm{PdN} 3$ propagating successfully to the soma. In these same neurons, 128 of the 130 action potentials reached the soma on each of the two PdN3 alone trials. Six S-cells were unaffected by the prepulse (all PdN3elicited action potentials propagated successfully to the soma). A one-way between-subjects ANOVA indicated a significant overall effect of the presence of the prepulse stimulus on action potential propagation for the three trials $\left(F_{(2,18)}=38.77, p<0.001\right)$. Post hoc Bonferroni comparisons indicated that the mean number of action potentials arriving at the soma for the first PdN3alone trial versus the PPI trial were significantly different from one another $(t=7.63, p<0.001)$, as they were for the PPI trial versus the following PdN3-alone trial $(t=7.63, p<0.001)$. The mean number of action potentials arriving at the S-cell soma elicited on the two PdN3 alone stimulus trials were identical and thus not significantly different from one another.

Together, these experiments indicate that stimulation of the prepulse pathway can block action potential propagation in axons of the startle pathway. Because the affected S-cells were not activated by the prepulse stimulus, this gating mechanism must involve the action of inhibitory neurons, making this a form of axo-axonic conduction block, the inhibition of actively propagating action potentials in one pathway by axons in another.

\section{The prepulse-elicited conduction block has the temporal features of behavioral PPI in Tritonia}

If conduction block mediates PPI, it should display its key phenomenological features - rapid onset and brief duration. To assess this, we next systematically tested the effectiveness of different stimulus onset intervals on conduction block of S-cell action potentials. In this isolated brain experiment, the prepulse stimulus was a $50 \mathrm{~Hz}, 20$ pulse shock train applied to cerebral ganglion nerves $\mathrm{C} 1-\mathrm{C} 5$. The startle stimulus consisted of a single brief stimulus to PdN3, sufficient to reliably elicit a single S-cell action potential. For every S-cell, conduction block was tested over a defined set of prepulse-startle interstimulus intervals (ISIs), ranging from 30, 60, 120, 250, 500, 1000, 2000, to $4000 \mathrm{~ms}$ from prepulse onset to the PdN3 shock. Each prepulse-PdN3 stimulus pairing was preceded and followed by a PdN3-alone trial, to test whether the $\mathrm{PdN} 3$ stimulus remained capable, throughout the experiment, of initiating an action potential in the S-cell's axon that, in the absence of inhibition, propagated successfully to the soma.

In this experiment, the PdN3-alone stimulus always elicited a single action potential that propagated successfully through the pedal ganglion to the S-cell soma in the pleural ganglion. However, when the PdN3 stimulus was preceded by the onset of a cerebral nerve $(\mathrm{C} 1-\mathrm{C} 5)$ prepulse train, significant conduction block of S-cell action potentials was observed (Fig. $3 A, B, 19$ S-cells, 3 preparations, Cochran Q Test, $p<0.0001)$. Significant conduction block occurred at ISIs of 250 and $500 \mathrm{~ms}$ (MarascuiloMcSweeney post hoc tests, $p<0.01$; Fig. 3C). In three additional $\mathrm{S}$-cells in two preparations the prepulse did not produce complete failure of the $S$-cell action potential, but instead reduced its amplitude and duration. In these cases the prepulse $\mathrm{C} 1-\mathrm{C} 5$ shocks produced an average reduction of $15.2 \%(8.2 \mathrm{mV})$ in the amplitude, and $28.1 \%(2.7 \mathrm{~ms}$ ) in the duration (measured from the base of the spike) of the PdN3-elicited S-cell action potential. These reduced-height action potentials are presumed to represent instances of conduction failure occurring sufficiently close to the soma that a reduced portion of the spike reached the cell body via electronic conduction. These results demonstrate the ability of the prepulse pathway to produce conduction block of orthodromic action potentials traveling in S-cell axons, with a rapidity of onset and briefness of duration similar to that characterized in prior studies of behavioral PPI in Tritonia (Mongeluzi et al., 1998).

\section{Conduction block also occurs in response to skin prepulses}

In our prior behavioral characterizations of PPI in Tritonia, we used tactile skin stimulation as the prepulse stimulus (Mongeluzi et al., 1998; Frost et al., 2003). Therefore, we next used a semiintact animal preparation, which allowed us to test whether skin prepulse stimuli could block action potential propagation in S-cell axons (Fig. 4A). Test action potentials were elicited as before by suction electrode stimulation of PdN3, and S-cells were selected that responded with a constant latency action potential to the nerve stimulus, indicating the presence of an axon in that nerve.

The cerebral nerves innervate the head region, including the rhinophore area (Willows et al., 1973). In an initial experiment (4 S-cells in 2 preparations) we tested whether a manually applied forceps pinch to the skin around the rhinophores administered $\sim 200$ ms before a single PdN3 stimulus could produce conduction block of the orthodromic S-cell action potential. In all four S-cells tested, when the PdN3 stimulus was delivered alone, an action potential arrived at the S-cell soma, whereas when the $\mathrm{PdN} 3$ stimulus was preceded by the skin pinch the action potential failed to do so (Fig. $4 B$ ).

To more precisely determine the effective prepulse-startle interval, a second experiment used skin shock $(50 \mathrm{~Hz}, 400 \mathrm{~ms}$ train of $1 \mathrm{~ms}$ pulses) rather than skin pinch as the prepulse, delivered via wires embedded in the skin in the area of the rhinophores. For every S-cell, conduction block was tested over the same defined set of ISIs used in the prior isolated brain experiment. As before, each prepulse-PdN3 pairing was preceded and followed by a 
PdN3-alone trial, to verify that the PdN3 stimulus remained capable of initiating an action potential in the S-cell's peripheral axon that could propagate successfully to the soma. We found that the action potentials elicited by the PdN3-alone trials always successfully reached the soma, whereas those paired with a skin prepulse significantly failed to do so (Fig. 4C,D; 16 cells, 6 preparations; Cochran Q test, $p<$ $0.0001)$. This inhibitory effect of the skin prepulse on action potential propagation depended on the prepulse-PdN3 shock ISI. Significant conduction block occurred at the 250 and $500 \mathrm{~ms}$ ISIs (Fig. 4E; post hoc Marascuilo-McSweeney tests). S-cell action potentials were not significantly blocked at prepulse-startle intervals shorter than $250 \mathrm{~ms}$ or $>500 \mathrm{~ms}$. These results are consistent with those using cerebral nerve stimulation as the prepulse (Fig. 3). In summary, the results so far are consistent with the hypothesis that PPI of the escape swim in Tritonia is mediated in part by prepulse-elicited conduction block of orthodromic action potentials traveling in S-cell axons of the startle pathway, reducing the ability of the S-cell population to activate the interneurons of the escape swim network.

\section{Evidence that interneuron Pl-9} mediates PPI of S-cell conduction block

In a prior study we identified an interneuron, $\mathrm{Pl}-9$ (Fig. $2 \mathrm{~A}$ ), that was both necessary and sufficient for skin shock prepulses to produce PPI of the Tritonia escape swim motor program (Frost et al., 2003). Pl-9 is activated by skin prepulse stimuli and produces fast, chloride-mediated monosynaptic IPSPs onto the afferent neurons (S-cells) of the startle pathway. This hyperpolarizing inhibition reduces transmitter release from the S-cell terminals, causing S-cell action potentials to less effectively excite their postsynaptic neurons in the startle circuit (Frost et al., 2003). Our observation that this inhibition was strong enough to produce a $50 \%$ decrease in S-cell input resistance measured at the soma (Frost et al., 2003) suggested that it might be strong enough to cause S-cell action potentials to fail while propagating the startle stimulus. Fills of Pl-9 with 5,6 carboxyfluorescein show that it sends a bilateral process through the pleural and pedal ganglia to where $\mathrm{PdN} 3$ enters the pedal ganglion (Fig. $5 A$ ). The fact that $\mathrm{Pl}-9$ travels the same pleural ganglion-to-PdN3 route taken by the axons of the S-cells used in this study encouraged us to test whether it could produce conduction block of their propagating action potentials.

If Pl-9 mediates PPI of the SMP and S-cell action potential propagation, it should be excited by the cerebral nerve stimuli used to produce these effects (Fig. 3). In the two preparations in which Pl-9 was recorded during $\mathrm{CN}$ stimulation, this was the case, with Pl-9 responding with peak firing rates of 43 and $59 \mathrm{~Hz}$, and a total of 31 and 60 spikes, respectively (Fig. 5B). This observation, together with prior results documenting $\mathrm{Pl}-9$ responsiveness to tactile skin stimuli (Frost et al., 2003), indicates that Pl-9 is strongly activated by the prepulse stimuli used in the present study.

We then tested whether direct, intracellular stimulation of Pl-9 could produce conduction block of incoming S-cell action potentials. PdN3-alone stimuli were alternated with trials on which the PdN3 stimulus came shortly after the onset of a Pl-9 train. As before, this alternating procedure was used to ensure that any failure of the S-cell action potential to reach the soma was due to the presence of the prepulse stimulus, rather than a failure of the PdN3 stimulus itself to initiate an S-cell action potential.

We found S-cell action potentials elicited by a PdN3-alone stimulus always propagated successfully to the S-cell soma. On the other hand, a co-penetrated Pl-9 neuron driven with a train of discrete intracellular current pulses at $20-50 \mathrm{~Hz}$ that began before the PdN3 stimulus was found to completely prevent the arrival of the S-cell action potential in the soma in all 17 preparations in which it was tested (Fig. $5 \mathrm{C}$; McNemar test for dichotomous nominal scale data, $p<0.001,20 \mathrm{~Hz}: 6$ cells, $40 \mathrm{~Hz}: 10$ cells, $50 \mathrm{~Hz}: 1$ cell). Such conduction block also reliably occurred when Pl-9 trains were driven with single depolarizing pulses $($ mean initial firing frequency $=38 \mathrm{~Hz}$, final frequency $=21 \mathrm{~Hz}$ ) that began before the PdN3 stimulus (McNemar test, $p<0.05,6$ cells, 4 preparations).

In the above cases, the conduction block was far enough from the S-cell soma that the incoming action potential completely failed to reach the recording electrode posted there. However, in some Pl-9 stimulation trials (as with cerebral nerve prepulse stimulation, Fig. 2 B3) a highly attenuated S-cell action potential was occasionally recorded (Fig. 5D). Such attenuated S-cell spikes occurred when Pl-9 was driven with either discrete trains of $2 \mathrm{~ms}$ intracellular current pulses $(20 \mathrm{~Hz}: 2$ cells, $40 \mathrm{~Hz}: 3$ cells, $50 \mathrm{~Hz}: 1$ cell; average attenuation: $54.0 \pm 17.8 \%, 6$ preparations) or with a single intracellular pulse of several seconds duration (mean initial 
A

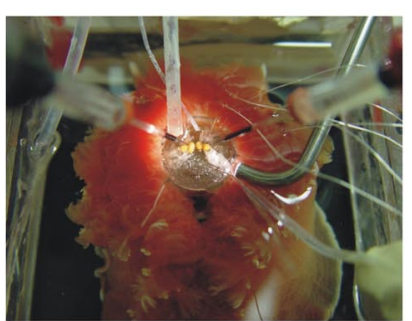

C

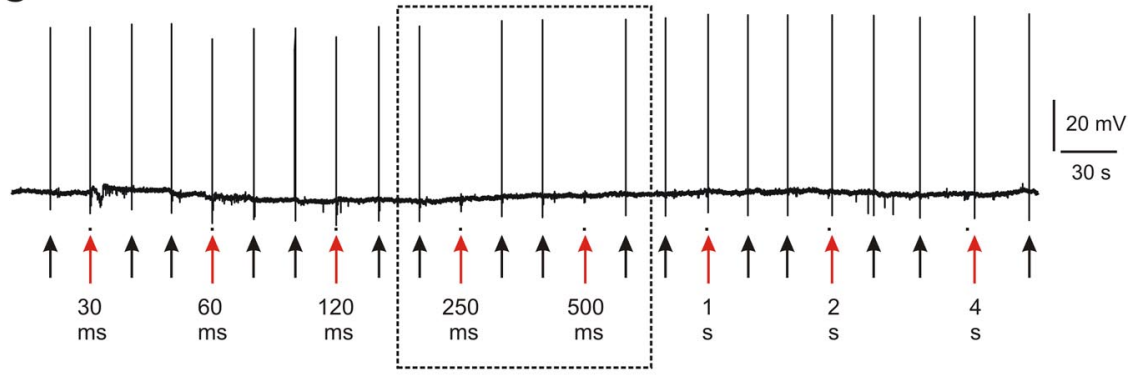

D
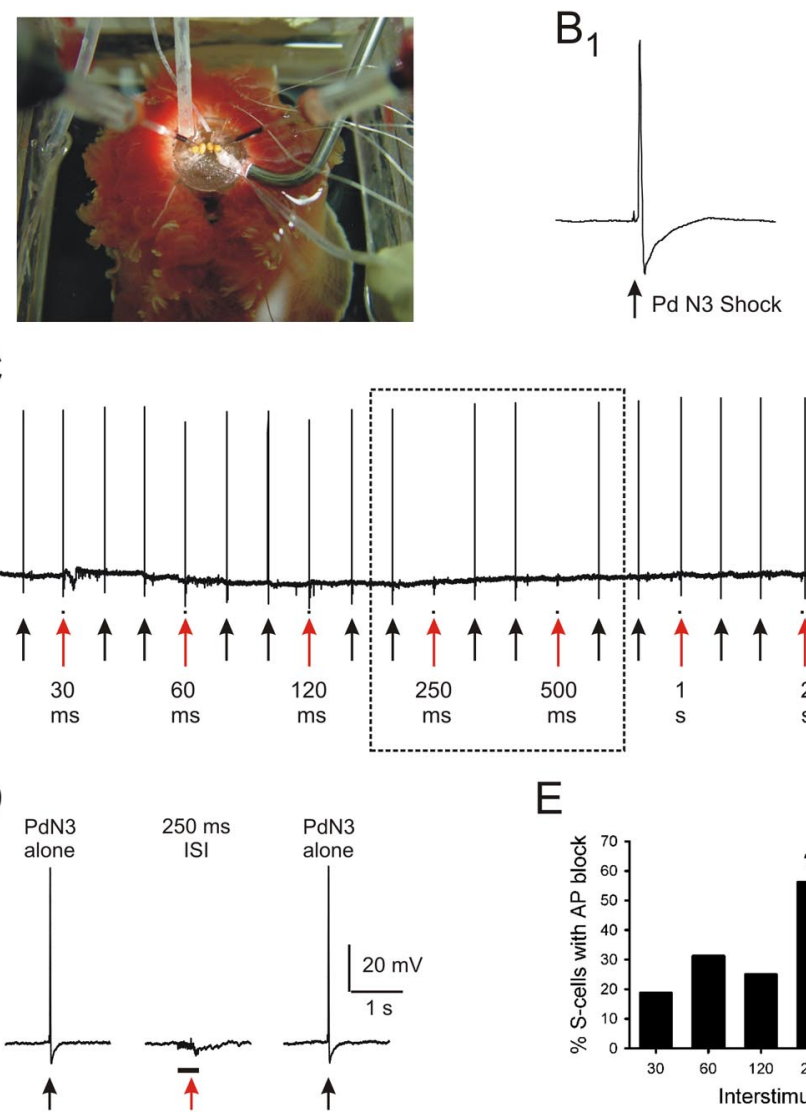

$\mathrm{B}_{2}$

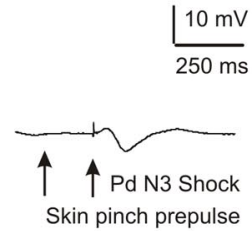

$\frac{10 \mathrm{mV}}{250 \mathrm{~ms}}$

$\mathrm{E}$

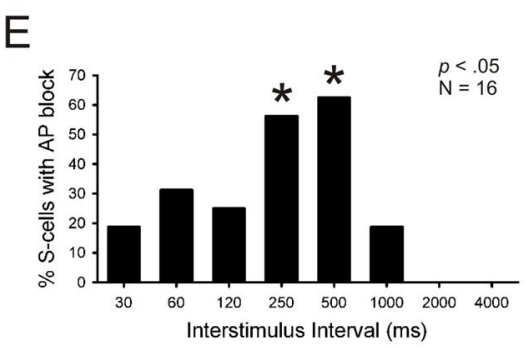

Figure 4. Skin shock prepulses produce a similarly brief period of conduction block. $A$, In these semi-intact animal preparations, the brain was pinned out on a Sylgard-covered platform, rendering the $S$-cells accessible for intracellular recording. $\boldsymbol{B}$, Delivery of a manual rhinophore pinch $\sim 200 \mathrm{~ms}$ before a PdN3 stimulus produced conduction block of the orthodromic PdN3-elicited S-cell action potential. $\boldsymbol{B 1}$, When a PdN3 stimulus was delivered alone, the $S$-cell action potential propagated successfully to the soma recording site. $\boldsymbol{B} \mathbf{2}$, When preceded by a skin pinch prepulse, the action potential failed to arrive at the soma recording site. $\boldsymbol{C}$, Use of skin shock prepulses to define the effective period of conduction block. Black arrows, PdN3-alone trials, which always elicited a single S-cell action potential that propagated successfully to the soma recording site. Red arrows, PPI trials, where the PdN3 stimulus, delivered at the arrow, was preceded by the skin shock prepulse stimulus ( $50 \mathrm{~Hz}$ train of 20 pulses), marked by the black dot near the arrowhead. The dotted box encloses the PPI trials on which S-cell action potential conduction block occurred. $\boldsymbol{D}$, Expanded view of the conduction block at the 250 ms interstimulus interval. $\boldsymbol{E}$, Group data from $16 \mathrm{~S}$-cells from 6 preparations, showing that significant conduction block occurred with skin-shock prepulse-PdN3 stimulation intervals of 250 and 500 ms. All 16 $\mathrm{S}$-cells received the complete stimulus sequence shown in $\boldsymbol{C}$.

firing frequency: $38 \mathrm{~Hz}$, final frequency: $26 \mathrm{~Hz}$, average attenuation: $34.0 \pm 13.6 \% ; 4$ cells, 4 preparations). As before, such shortened $\mathrm{S}$-cell spikes are interpreted to result from active propagation failure that occurred close enough to the soma that a portion of the spike reached it via electrotonic conduction.

These results demonstrate that the prepulse-activated interneuron $\mathrm{Pl}-9$ can block actively propagating action potentials in the startle pathway S-cell axons. In a final experiment we used photoinactivation to test whether Pl-9 might not just be sufficient, but also necessary for CN-mediated PPI of S-cell spike propagation. In this isolated brain experiment, an S-cell was first impaled that had an axon in $\mathrm{PdN} 3$, and whose spike propagation was blocked by an immediately preceding stimulus to $\mathrm{CN} 1,4,5$ (Fig. 5E1). An intracellular electrode containing 5,6 carboxyfluorescein was then used to locate an ipsilateral Pl-9 neuron (there are one or two in each pleural ganglion, located below the surface). The S-cell electrode was then removed and dye was injected into Pl-9 via iontophoresis. Once Pl-9 was sufficiently filled that its extended axonal processes could be seen with the Leica MZ FLIII fluorescence stereomicroscope used for these experiments, the light was left on for $20 \mathrm{~min}$ to $2 \mathrm{~h}$ to kill the neuron. The same
S-cell was then repenetrated and the PPI test was repeated. We found that in three preparations in which we successfully found and killed Pl-9, the ability of a closely preceding $\mathrm{CN}$ stimulus to produce conduction block of S-cell action potentials was eliminated (Fig. 5E2). Loss of one Pl-9 reduced but did not eliminate the number of CN-elicited IPSPs recorded in the S-cell, consistent with there being additional Pl-9 s contributing to this input, as can be seen in Figure 5B. Together, these findings support the conclusion that Pl-9 mediates the conduction block effect of CN stimuli on S-cell action potential propagation.

\section{Discussion}

This study demonstrates a novel cellular mechanism for PPI: prepulse-elicited conduction block of action potentials propagating in axons of the startle pathway. Blocking arrival of the startle stimulus is clearly a potent mechanism for reducing behavioral responsiveness to it. We further identified a prepulse-activated inhibitory interneuron, Pl-9, and showed it to be both necessary and sufficient for prepulse stimuli to produce this conduction block effect. Pl-9 has previously been shown to be both necessary and sufficient to mediate PPI of the Tritonia SMP, in part by producing presynaptic inhibition of S-cell transmitter release (Frost et al., 2003). Directly driven Pl-9 spike trains produce an increased-conductance hyperpolarizing chloride IPSP in the S-cells sufficient to reduce their input resistance by $50 \%$ (Frost et al., 2003). Both the hyperpolarization and the conductance increase are appropriate mechanisms for hindering action potential propagation in S-cell axons. Shunting inhibition is a well known contributor to presynaptic inhibition at synaptic release sites (Clarac and Cattaert, 1996; Cattaert and El Manira, 1999; MacDermott et al., 1999; Rudomin and Schmidt, 1999) and has been suggested to play a role in conduction block of axons as well (Wall, 1995; Evans et al., 2003; Verdier et al., 2003).

A characteristic feature of behavioral PPI is its brevity: 60$1000 \mathrm{~ms}$ in vertebrates (Johansson et al., 1995; Kumari et al., 1999, 2000; Braff et al., 2001; Geyer et al., 2001; Winslow et al., 2002) and 120-2500 ms in Tritonia (Mongeluzi et al., 1998). The conduction block characterized here had an appropriately brief duration to mediate PPI, with significant block produced at stimulus intervals of 250-1000 ms, depending on the paradigm used.

Axons are traditionally envisioned as highly reliable transmission lines for action potentials (Mackenzie et al., 1996). However, this is not always the case. For example, there are many published examples of intrinsic axonal conduction block, where action potential conduction fails without the involvement of other neurons. Such conduction failure can result from prolonged highfrequency stimulation (Applegate and Burke, 1989; Miller et al., 1995; Kiernan et al., 1996; Debanne, 2004), or during passage of 
A

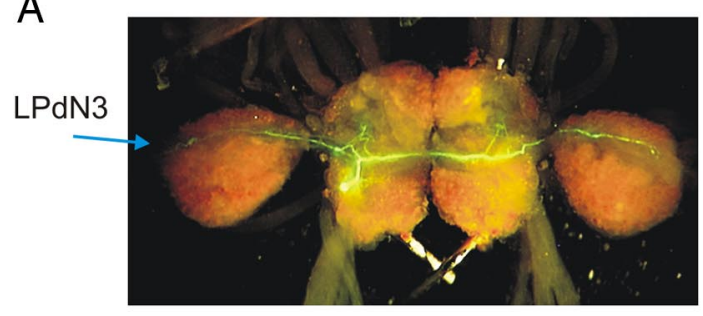

C

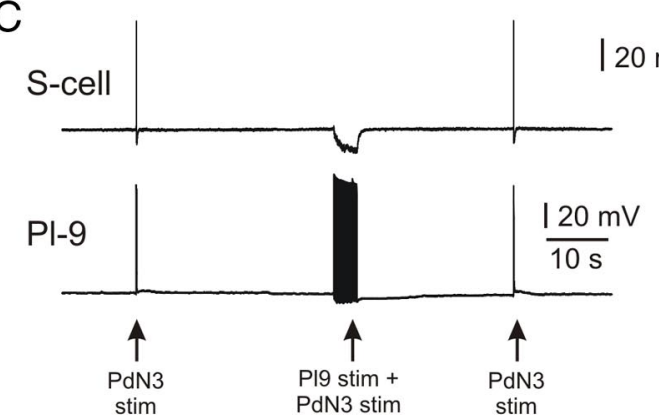

$\mathrm{E}_{1}$
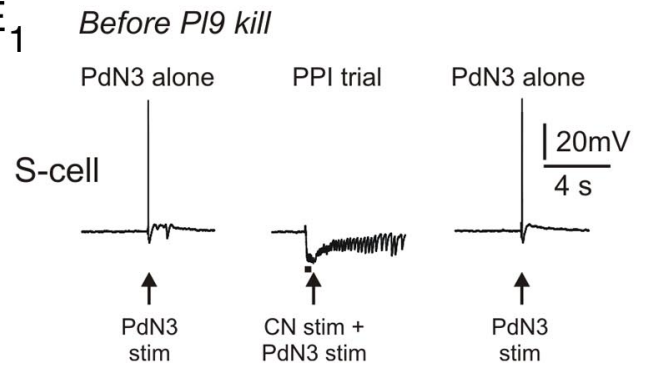

B
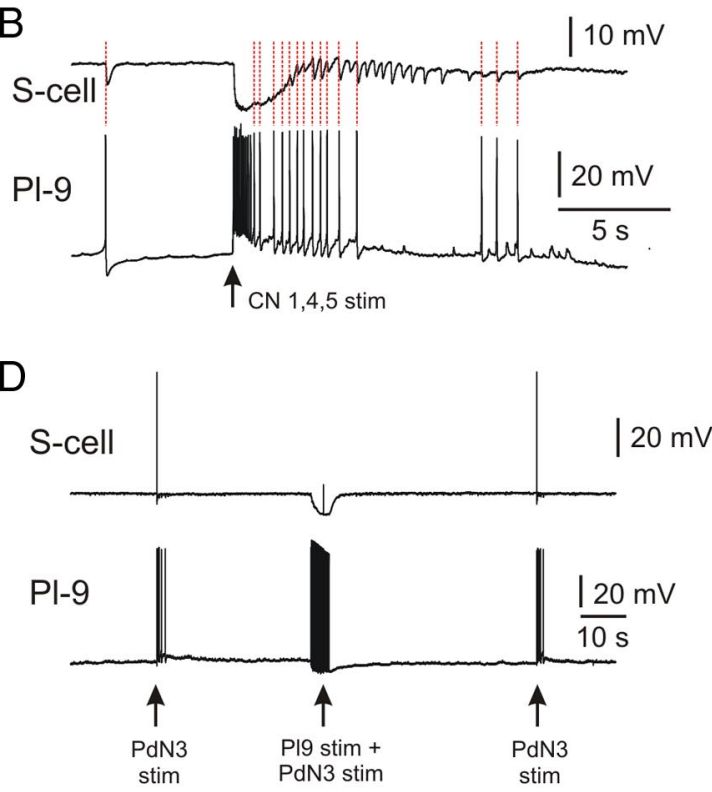

$\mathrm{E}_{2}$
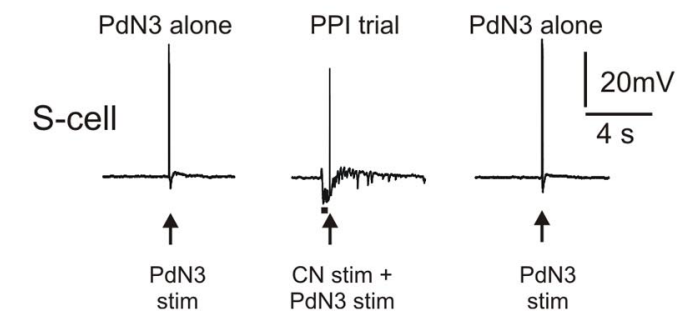

Figure 5. PI-9 mediates prepulse-elicited conduction block of S-cell action potentials. $\boldsymbol{A}$, Carboxyfluorescein fill of PI-9. PI-9 sends a bilateral axonal process across the pleural and pedal ganglia to the entry points of PdN3 on each side of the brain. The S-cells used in this study send a process along this same route into PdN3, providing extended opportunities for inhibitory synapses from PI- 9 onto S-cell axons. B, PI-9 is strongly activated by prepulse stimulation of cerebral ganglion nerves $1,4,5(50 \mathrm{~Hz}, 2$ s). A simultaneously recorded S-cell shows one-for-one IPSPs with the PI- 9 action potentials (red dotted lines). The S-cell receives additional IPSPs, consistent with input from one or more additional PI-9 neurons. $C$, A single PI-9 neuron is sufficient to produce conduction block of S-cell action potentials. Left arrow, A PdN3-alone stimulus elicited an S-cell action potential that reached the soma intracellular recording site. Middle arrow, When the PdN3 stimulus was delivered during a PI-9 train driven by discrete intracellular current pulses $(20 \mathrm{~Hz}, 4 \mathrm{~s})$ the $S$-cell action potential failed to arrive at the soma. Right arrow, A PdN3-alone stimulus again elicited an action potential that propagated to the soma. $\boldsymbol{D}$, In some trials, PI-9 stimulation $(20 \mathrm{~Hz}, 4 \mathrm{~s})$ blocked active propagation sufficiently close to the soma that an electrotonically conducted remnant of the action potential reached the S-cell electrode. $\boldsymbol{E}$, PI-9 is necessary for cerebral nerve stimuli to produce prepulse-elicited conduction block of S-cell spike propagation. $\boldsymbol{E}$, Before cell-kill of a single PI-9, a 50 Hz 5 V 20 pulse stimulus train applied to CN 1,4,5 (bar) beginning 0.4 s before a single 2 V stimulus to PdN3 (arrow) produced block of the S-cell action potential elicited by the PdN3 stimulus. E2, After a PI-9 neuron was located, iontophoretically filled with carboxyfluorescein, and then killed by exposure to several minutes of $488 \mathrm{~nm}$ light, the same cerebral nerve stimulus no longer produced conduction block of the PdN3-elicited S-cell action potential. Killing one PI-9 can be seen to reduce the CN-elicited inhibitory input to the S-cell.

the action potential from smaller to larger diameter regions of the axon, e.g., at branch points (Macagno et al., 1987; Baccus et al., 2000; Debanne, 2004). Conduction failure also occurs in pathological conditions, such as multifocal neuropathy (Franssen and van den Bergh, 2006; Nodera et al., 2006), Guillain-Barre syndrome (Kuwabara et al., 2002), and multiple sclerosis (Smith and McDonald, 1999). In contrast, modulatory transmitters can enhance action potential propagation (Ballo et al., 2012).

The type of conduction failure documented here, block of action potentials in axons of one neuron by activity in another, is less widely appreciated. While never before associated with PPI, evidence has been accumulating for some time (Barron and Matthews, 1935) that action potential propagation may be under the control of inhibitory interneurons. Wall and colleagues provided indirect evidence that GABAergic interneurons can block propagation in the axons of myelinated sensory afferents in the mammalian spinal cord (Wall, 1994; Wall and McMahon, 1994), and termed this "pre-presynaptic inhibition" to clarify that they were studying inhibition in the conducting portion of axons, not in their terminal synaptic regions. Wall thus explicitly distinguished two separate locations of this presynaptic mechanism-axons and axon terminals (Wall, 1998). More recent studies have demonstrated GABAergic block of action potential propagation in the long, electrically active lateral dendrites of mammalian olfactory bulb mitral cells (Xiong and Chen, 2002), the axons of mammalian jaw muscle spindle afferents (Verdier et al., 2003), and axons of spider mechanoreceptors (Gingl et al., 2004). However, none of these studies identified specific inhibitory neurons producing the conduction block.

In invertebrates, axo-axonic conduction block has previously been demonstrated in Aplysia californica. In one study, stimulating pedal nerve 8 just before pedal nerve 9 was found to block conduction of orthodromic action potentials in sensory neurons with axons in pedal nerve 9 (Clatworthy and Walters, 1993). In others, interneurons have been identified that block action potential conduction in the lateral processes of buccal sensory neurons (Evans et al., 2003, 2005). However, to our knowledge, in no preceding study has a behavioral role for 
axo-axonic block of actively propagating action potentials been demonstrated.

Summarizing results from our prior (Frost et al., 2003) and present studies, PPI in Tritonia is mediated by a combined set of mechanisms: (1) presynaptic inhibition by Pl-9 of transmitter release from S-cell synapses onto several circuit interneurons, (2) postsynaptic inhibition of several circuit interneurons by neurons Pl-9 and Pl-10, and (3) conduction block of S-cell action potential propagation by $\mathrm{Pl}-9$, which given its all-or-nothing nature, may be the most potent mechanism of those so far described. These different mechanisms are nicely complimentary in function. First, the prepulse-elicited conduction block will completely prevent many inbound action potentials in the sensory axons of the startle pathway from reaching their release sites. For those that propagate successfully through the inhibited region of the axon, their impact will be reduced by the additional mechanisms of presynaptic inhibition of transmitter release from the S-cell terminals, and postsynaptic inhibition of S-cell target interneurons (Frost et al., 2003).

Prepulse inhibition has attracted significant interest because PPI deficits appear to be a core feature of schizophrenia, where reduced sensory gating has been linked to several cognitive disorders of the disease, including psychosis (Braff et al., 2001). Our prior (Frost et al., 2003) and present findings in Tritonia constitute the first specific cellular mechanisms for PPI, and raise the question of whether defects in these mechanisms might be present in schizophrenia. If so, therapies targeted to these specific neuronal defects could be sought, with the goal of developing improved treatment. While in the present study we investigated axo-axonic conduction block in the context of a PPI stimulus paradigm, this potent gating mechanism presumably plays additional roles in Tritonia and other organisms.

\section{References}

Applegate C, Burke D (1989) Changes in excitability of human cutaneous afferents following prolonged high-frequency stimulation. Brain 112: 147-164. CrossRef Medline

Baccus SA, Burrell BD, Sahley CL, Muller KJ (2000) Action potential reflection and failure at axon branch points cause stepwise changes in EPSPs in a neuron essential for learning. J Neurophysiol 83:1693-1700. Medline

Bakshi VP, Swerdlow NR, Geyer MA (1994) Clozapine antagonizes phencyclidine-induced deficits in sensorimotor gating of the startle response. J Pharmacol Exp Ther 271:787-794. Medline

Ballo AW, Nadim F, Bucher D (2012) Dopamine modulation of Ih improves temporal fidelity of spike propagation in an unmyelinated axon. J Neurosci 32:5106-5119. CrossRef Medline

Barak S (2009) Modelling cholinergic aspects of schizophrenia: focus on the antimuscarinic syndrome. Behav Brain Res 204:335-351. Medline

Barron DH, Matthews BH (1935) Intermittent conduction in the spinal cord. J Physiol 85:73-103. Medline

Bosch D, Schmid S (2008) Cholinergic mechanism underlying prepulse inhibition of the startle response in rats. Neuroscience 155:326-335. CrossRef Medline

Bouret S, Sara SJ (2005) Network reset: a simplified overarching theory of locus coeruleus noradrenaline function. Trends Neurosci 28:574-582. Medline

Braff DL, Grillon C, Geyer MA (1992) Gating and habituation of the startle reflex in schizophrenic patients. Arch Gen Psychiatry 49:206-215. Medline

Braff DL, Geyer MA, Swerdlow NR (2001) Human studies of prepulse inhibition of startle: normal subjects, patient groups, and pharmacological studies. Psychopharmacology 156:234-258. CrossRef Medline

Cattaert D, El Manira A (1999) Shunting versus inactivation: analysis of presynaptic inhibitory mechanisms in primary afferents of the crayfish. J Neurosci 19:6079-6089. Medline

Clarac F, Cattaert D (1996) Invertebrate presynaptic inhibition and motor control. Exp Brain Res 112:163-180. Medline
Clarac F, Pearlstein E (2007) Invertebrate preparations and their contribution to neurobiology in the second half of the 20th century. Brain Res Rev 54:113-161. Medline

Clatworthy AL, Walters ET (1993) Activity-dependent depression of mechanosensory discharge in Aplysia. J Neurophysiol 70:1195-1209. Medline

Debanne D (2004) Information processing in the axon. Nat Rev Neurosci 5:304-316. Medline

Evans CG, Jing J, Proekt A, Rosen SC, Cropper EC (2003) Frequencydependent regulation of afferent transmission in the feeding circuitry of Aplysia. J Neurophysiol 90:3967-3977. CrossRef Medline

Evans CG, Romero A, Cropper EC (2005) Inhibition of afferent transmission in the feeding circuitry of Aplysia: persistence can be as important as size. J Neurophysiol 93:2940-2949. CrossRef Medline

Fendt M, Koch M (1999) Cholinergic modulation of the acoustic startle response in the caudal pontine reticular nucleus of the rat. Eur J Pharmacol 370:101-107. Medline

Fendt M, Li L, Yeomans JS (2001) Brain stem circuits mediating prepulse inhibition of the startle reflex. Psychopharmacology 156:216-224. CrossRef Medline

Franssen H, van den Bergh PY (2006) Nerve conduction studies in polyneuropathy: practical physiology and patterns of abnormality. Acta Neurol Belg 106:73-81. Medline

Friedman JI (2004) Cholinergic targets for cognitive enhancement in schiziophrenia: a focus on cholinesterase inhibitors and muscarinic agonists. Psychopharmacology 174:45-53. Medline

Frost WN, Hoppe TA, Wang J, Tian LM (2001) Swim initiation neurons in Tritonia diomedea. Am Zool 41:952-961. CrossRef

Frost W, Tian LM, Hoppe T, Mongeluzi D, Wang J (2003) A cellular mechanism for prepulse inhibition. Neuron 40:991-1001. CrossRef Medline

Getting P (1976) Afferent neurons mediating escape swimming of the marine mollusk, Tritonia. J Comp Physiol 110:271-286. CrossRef

Getting PA (1983) Neural control of swimming in Tritonia. Symp Soc Exp Biol 37:89-128. Medline

Geyer MA, Kreds-Thomson K, Braff DL, Swerdlow NR (2001) Pharmacological studies of prepulse inhibition models of sensorimotor gating deficits in schizophrenia: a decade in review. Psychopharmacology 156:117154. CrossRef Medline

Gingl E, French AS, Panek I, Meisner S, Torkkeli PH (2004) Dendritic excitability and localization of GABA-mediated inhibition in spider mechanoreceptor neurons. Eur J Neurosci 20:59-65. Medline

Graham F (1992) Attention: the heartbeat, the blink, and the brain. In: Attention and information processing in infants and adults: perspectives from human and animal research (Campbell B, Hayne H, Richardson R, eds). Hillsdale, NJ: Erlbaum.

Hamm AO, Weike AI, Schupp HT (2001) The effect of neuroleptic medication on prepulse inhibition in schizophrenic patients: current status and future issues. Psychopharmacology 156:259-265. CrossRef Medline

Hoffman H, Ison J (1992) Reflex modification and the analysis of sensory processing in development and comparative research. In: Attention and information processing in infants and adults: perspectives from human and animal research (Campbell B, Hayne H, Richardson R, eds). Hillsdale, NJ: Erlbaum.

Homma Y, Skinner RD, Garcia-Rill E (2002) Effects of pedunculopontine nucleus (PPN) stimulation on caudal pontine reticular formation $(\mathrm{PnC})$ neurons in vitro. J Neurophysiol 87:3033-3047. Medline

Hume RI, Getting PA, Del Beccaro MA (1982) Motor organization of Tritonia swimming. I. Quantitative analysis of swim behavior and flexion neuron firing patterns. J Neurophysiol 47:60-74. Medline

Johansson C, Jackson DM, Zhang J, Svensson L (1995) Prepulse inhibition of acoustic startle, a measure of sensorimotor gating: effects of antipsychotics and other agents in rats. Pharmacol Biochem Behav 52:649-654. Medline

Karper LP, Freeman GK, Grillon C, Morgan CA 3rd, Charney DS, Krystal JH (1996) Preliminary evidence of an association between sensorimotor gating amd distractability in psychosis. J Neuropsychiatry Clin Neurosci 8:60-66. Medline

Kiernan MC, Mogyoros I, Burke D (1996) Changes in excitability and impulse transmission following prolonged repetitive activity in normal subjects and patients with a focal nerve lesion. Brain 119:2029-2037. CrossRef Medline

Koch M, Kungel M, Herbert H (1993) Cholinergic neurons in the pe- 
dunculopontine tegmental nucleus are involved in the mediation of prepulse inhibition of the acoustic startle response in the rat. Exp Brain Res 97:71-82. Medline

Kumari V, Soni W, Sharma T (1999) Normalization of information processing deficits in schizophrenia with clozapine. Am J Psychiatry 156: 1046-1051. Medline

Kumari V, Soni W, Matthew VM, Sharma T (2000) Prepulse inhibition of the startle response in men with schizophrenia: effects of age or onset of illness, symptoms, and medication. Arch Gen Psychiatry 57:609-614. Medline

Kuwabara S, Ogawara K, Sung JY, Mori M, Kanai K, Hattori T, Yuki N, Lin CS, Burke D, Bostock H (2002) Differences in membrane properties of axonal and demyelinating Guillain-Barre syndromes. Ann Neurol 52: 180-187. Medline

Macagno E, Muller KJ, Pitman RM (1987) Conduction block silences parts of a chemical synapse in the leech central nervous system. J Physiol 387: 649-664. Medline

MacDermott AB, Role LW, Siegelbaum SA (1999) Presynaptic ionotropic receptors and the control of transmitter release. Annu Rev Neurosci 22: 443-485. Medline

Mackenzie PJ, Umemiya M, Murphy TH (1996) $\mathrm{Ca}^{2+}$ imaging of CNS axons in culture indicates reliable coupling between single action potentials and distal functional release sites. Neuron 16:783-795. CrossRef Medline

Megalou EV, Brandon CJ, Frost WN (2009) Evidence that the swim afferent neurons of tritonia diomedea are glutamatergic. Biol Bull 216:103-112. Medline

Miller TA, Kiernan MC, Mogyoros I, Burke D (1995) Activity-dependent changes in impulse conduction in normal human cutaneous axons. Brain 118:1217-1224. CrossRef Medline

Mongeluzi DL, Hoppe TA, Frost WN (1998) Prepulse inhibition of the Tritonia escape swim. J Neurosci 18:8467-8472. Medline

Nodera H, Bostock H, Izumi Y, Nakamura K, Urushihara R, Sakamoto T, Murase N, Shimazu H, Kusunoki S, Kaji R (2006) Activity-dependent conduction block in multifocal motor neuropathy: magnetic fatigue test. Neurology 67:280-287. CrossRef Medline

Perry W, Braff DL (1994) Information-processing deficits and thought disorder in schizophrenia. Am J Psychiatry 151:363-367. Medline

Pittenger C, Kandel ER (2003) In search of general mechanisms for longlasting plasticity: Aplysia and the hippocampus. Phil Trans R Soc Lond B 358:757-763.

Quednow BB, Frommann I, Berning J, Kühn KU, Maier W, Wagner M (2008) Impaired sensorimotor gating of the acoustic startle response in the prodrome of schizophrenia. Biol Psychiatry 64:766-773. Medline

Rudomin P, Schmidt RF (1999) Presynaptic inhibition in the vertebrate spinal cord revisited. Exp Brain Res 129:1-37. Medline

Sandeman D (1999) Homology and convergence in vertebrate and invertebrate nervous systems. Naturwissenschaften 86:378-387. CrossRef Medline

Sattelle DB, Buckingham SD (2006) Invertebrate studies and their ongoing contributions to neuroscience. Invert Neurosci 6:1-3. Medline

Schofield BR, Motts SD (2009) Projections from auditory cortex to cholin- ergic cells in the midbrain tegmentum of guinea pigs. Brain Res Bull 80:163-170. Medline

Selverston A (1999) What invertebrate circuits have taught us about the brain. Brain Res Bull 50:439-440. Medline

Slawsky M (1979) Presynaptic inhibition in the marine mollusk Tritonia Diomedea. PhD thesis, Stanford University.

Smith KJ, McDonald WI (1999) The pathophysiology of multiple sclerosis: the mechanisms underlying the production of symptoms and the natural history of the disease. Philos Trans R Soc Lond B Biol Sci 354:1649-1673. Medline

Swerdlow NR, Geyer MA (1993) Prepulse inhibition of acoustic startle response in rats after lesions of the pedunculopontine tegmental nucleus. Behav Neurosci 107:104-117. Medline

Verdier D, Lund JP, Kolta A (2003) GABAergic control of action potential propagation along axonal branches of mammalian sensory neurons. J Neurosci 23:2002-2007. Medline

Wall PD (1994) Control of impulse conduction in long range branches of afferents by increases and decreases of primary afferent depolarization in the rat. Eur J Neurosci 6:1136-1142. Medline

Wall PD (1995) Do nerve impulses penetrate terminal arborizations? A prepresynaptic control mechanism. Trends Neurosci 18:99-103. Medline

Wall PD (1998) Some unanswered questions about the mechanisms and function of presynaptic inhibition. In: Presynaptic inhibition and neural control (Rudomin P, Romo R, Mendell LM, eds), pp 228-241. New York: Oxford UP.

Wall PD, McMahon SB (1994) Long range afferents in rat spinal cord. III. Failure of impulse transmission in axons and relief of the failure after rhizotomy of dorsal roots. Philos Trans R Soc Lond B Biol Sci 343:211-223. Medline

Weike AI, Bauer U, Hamm AO (2000) Effective neuroleptic medication removes prepulse inhibtion deficits in schizophrenia patients. Biol Psychiatry 47:61-70. Medline

Willows AO, Dorsett DA, Hoyle G (1973) The neuronal basis of behavior in Tritonia. I. Functional organization of the central nervous system. J Neurobiol 4:207-237. CrossRef Medline

Winslow J, Parr LA, Davis M (2002) Acoustic startle, prepulse inhibition, and fear-potentiated startle measured in rhesus monkeys. Biological Psychiatry 51:859-866. Medline

Xiong W, Chen WR (2002) Dynamic gating of spike propagation in the mitral cell lateral dendrites. Neuron 34:115-126. CrossRef Medline

Yeomans JS, Lee J, Yeomans MH, Steidl S, Li L (2006) Midbrain pathways for prepulse inhibition and startle activation in rat. Neuroscience 142: 921-929. CrossRef Medline

Ziermans TB, Schothorst PF, Sprong M, Magnée MJ, van Engeland H, Kemner C (2012) Reduced prepulse inhibition as an early vulnerability marker of the psychosis prodrome in adolescence. Schizophr Res 134:1015. Medline

Ziermans T, Schothorst P, Magnée M, van Engeland H, Kemner C (2011) Reduced prepulse inhibition in adolescents at risk for psychosis: a 2-year follow-up study. J Psychiatry Neurosci 36:127-134. Medline 